\title{
Non-HDL Cholesterol to HDL Cholesterol Ratio Measurement
}

National Cancer Institute

\section{Source}

National Cancer Institute. Non-HDL Cholesterol to HDL Cholesterol Ratio Measurement. NCI Thesaurus. Code C120644.

The determination of the ratio of non-HDL cholesterol compared to HDL cholesterol present in a sample. The measurement may be expressed as a ratio or percentage. 